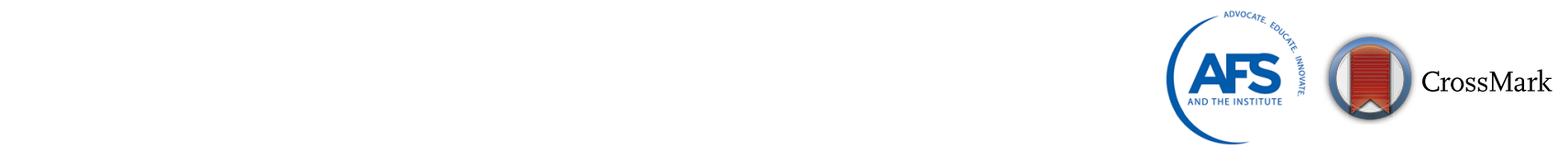

\title{
ERRATUM TO: A CONTRIBUTION TO NEW MATERIAL STANDARDS FOR DUCTILE IRONS AND AUSTEMPERED DUCTILE IRONS
}

\author{
Franco Zanardi $(1)$ \\ Zanardi Fonderie SpA, Minerbe, VR, Italy \\ Franco Bonollo \\ Department of Management and Engineering, University of Padova, Vicenza, Italy \\ Giuliano Angella \\ CNR-ICMATE, Milan, Italy \\ Nicola Bonora, Gianluca Iannitti, and Andrew Ruggiero \\ Department of Civil and Mechanical Engineering, University of Cassino and Southern Lazio, Cassino, Italy
}

Copyright $(\subset) 2017$ American Foundry Society

DOI 10.1007/s40962-017-0145-8

\section{Erratum to: International Journal of Metalcasting/ \\ Volume 11, Issue 1, 2017, pp. 136-147 \\ DOI 10.1007/s40962-016-0095-6}

In the original article, Andrew Ruggiero's given name was misspelled. It is correct as shown in this erratum. 